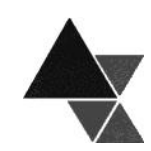

SEGURANCA

alimentar e nutricional

\title{
Sanitização de alface americana com água ozonizada para inativação de Escherichia coli $\mathrm{O} 157: \mathrm{H7}$
}

\author{
Daniel Augusto Cavalcante ${ }^{1}$, Bruno Ricardo de Castro Leite Júnior ${ }^{2}$, Alline Artigiani Lima \\ Tribst $^{2}$, Marcelo Cristianini ${ }^{3}$
}

As hortaliças folhosas, especialmente a alface, têm sido identificadas como veículos significativos de patógenos relevantes em saúde pública. O objetivo deste trabalho foi avaliar a redução de Escherichia coli O157:H7 intencionalmente inoculada na alface após sanitização da hortaliça com água ozonizada. Dez amostras de alface americana foram inoculadas com E. coli $\mathrm{O} 157: \mathrm{H} 7$ e submetidas à sanitização em água ozonizada na concentração de $1 \mathrm{mg} . \mathrm{L}^{-1}$ durante um minuto. A contaminação inicial das alfaces foi da ordem de $10^{5}-10^{6}$ UFC.g ${ }^{-1}$, e o processo de sanitização resultou em reduções decimais entre 2,40 e 4,49, sendo a variação observada possivelmente função da concentração inicial inoculada e da heterogeneidade da superfície da alface, o que pode afetar a aderência do micro-organismo nas amostras e, consequentemente, a efetividade do processo de sanitização. Assim, a utilização de água ozonizada mostra ser uma tecnologia promissora na etapa de sanitização em alface.

Palavras-chave: micro-organismo patogênico, ozônio, processos não térmicos.

\section{Sanitization of iceberg lettuce with ozonated water to inactivate Escherichia coli O157:H7}

The leafy vegetables, especially lettuce, has been identified as significant vehicles of pathogens relevant to public health. This study aimed to determine the Escherichia coli O157: H7 reduction in intentionally inoculated lettuce through sanitation using ozonated water. Ten samples of lettuce were inoculated with E. coli O157: $\mathrm{H} 7$ and sanitized by ozonated water at concentration of $1.0 \mathrm{mg} \cdot \mathrm{L}^{-1}$ for one minute. The initial E coli lettuce load ranged between $10^{5}-10^{6} \mathrm{CFU} \cdot \mathrm{g}^{-1}$ and the sanitation process promoted 2.40 to 4.49 decimal reductions. This variation on microbial reduction can be attributed to E. coli initial load and to heterogeneous lettuce surface, which affects the E. coli adherence on samples and, consequently, the sanitizing process efficacy. Therefore, the ozonated water is a promising technology for lettuce sanitizing step.

Key-words: pathogenic micro-organism, ozone, non-thermal processes.

\footnotetext{
${ }^{1}$ I Comando da Aeronáutica, Fazenda da Aeronáutica de Pirassununga, Pirassununga, SP, Brasil. E-mail: cavalcante.dac@uol.com.br

${ }^{2}$ Universidade Estadual de Campinas (UNICAMP), Faculdade de Engenharia de Alimentos (FEA), Departamento de Tecnologia de Alimentos, Campinas, SP, Brasil.E-mail:brunorclj@gmail.com, alline.lima.tribst@gmail.com

${ }^{3}$ Universidade Estadual de Campinas (UNICAMP), Faculdade de Engenharia de Alimentos (FEA), Departamento de Tecnologia de Alimentos. Correspondência: Rua Monteiro Lobato nº 80, CEP 13083-862, Telefone: (19)3521-7592, Campinas, SP, Brasil. E-mail: olecram@fea.unicamp.br
} 


\section{INTRODUÇÃO}

A alface (Lactuca sativa $L$ ) é a hortaliça folhosa mais consumida no Brasil e no mundo. Os hábitos alimentares da população evidenciam essa condição que é favorecida pela fácil aquisição do produto, pelo seu sabor, pela qualidade nutritiva e por ser uma hortaliça de baixo custo [1]. Entretanto, a contaminação da hortaliça é um fator limitante para sua comercialização. Condições sanitárias desfavoráveis nas áreas rurais e urbanas favorecem essa contaminação, transformando os vegetais em veículos de transmissão de patógenos. Desse modo, pode-se afirmar que a contaminação pode ocorrer em todas as etapas da cadeia produtiva, englobando plantio, processamento, comercialização e consumo [2].

Embora perigos químicos e físicos sejam preocupantes, os perigos específicos para vegetais minimamente processados são prioritariamente microbiológicos. Vários surtos de gastrenterites humanas têm sido relacionados ao consumo de frutas e hortaliças contaminadas com estipes patogênicas de Escherichia coli [3], cuja presença em alimentos indica condições higiênicas insatisfatórias do produto.

De acordo com a Food and Drug Administration (FDA), dos Estados Unidos da América, a dose infecciosa para E. coli $\mathrm{O} 157: \mathrm{H} 7$ é desconhecida. No entanto, a compilação de dados de surtos indica que 10 células podem provocar danos à saúde do consumidor [4]. Em sua pesquisa, Bosilevac \& Koohmaraie [5] afirmam que a maioria dos surtos infecciosos causados por E.coli enterohemorrágicas foi ocasionado por linhagem de E. coli O157:H7.

Nos últimos anos, a segurança de frutas e hortaliças tem sido foco de muitos trabalhos que utilizam métodos físicos, químicos ou biológicos para reduzir ou eliminar patógenos destes produtos [ $[$. A escolha do procedimento mais efetivo de descontaminação deve considerar a eliminação de micro-organismos patogênicos sem causar impactos nas características nutricionais e sensoriais do produto.

Tecnologias tradicionais de sanitização utilizam soluções de hipoclorito e compostos de quaternário de amônio, que, apesar de efetivas, podem causar danos à saúde do consumidor [7]. Desta forma, observa-se a crescente necessidade de desenvolvimento de um novo método de sanitização seguro.
A alta capacidade oxidante do ozônio o torna uma interessante substância sanitizante, aplicada para tratamento de águas na Europa desde o início do século XX ${ }^{[8]}$. O FDA regulamenta a utilização do ozônio como método seguro para desinfecção de alimentos e unidade processadoras de alimentos quando combinado com boas práticas de fabricação desde 1997, sendo Geralmente Reconhecido como Seguro (GRAS) [9]. No Brasil, a Agência Nacional de Vigilância Sanitária regulamenta a utilização de ozônio apenas para o tratamento de águas ${ }^{[10] .}$

O ozônio é eficaz contra bactéria, bolores, leveduras e protozoários [11], além de possuir efeito inibitório sobre E. coli $\mathrm{O} 157: \mathrm{H} 7$ tanto em suspensão [12], como em frutas e hortaliças das quais pode-se destacar maça e alfafa [13,14]. Esse processo tem sido utilizado como método de sanitização de água [11], de frutas frescas fatiadas e de vegetais [15], portanto, o uso de água ozonizada tem emergido com uma interessante alternativa de sanitização devido a sua eficiência em baixas concentrações e em um curto período de tempo, e sua decomposição em produtos não tóxicos ${ }^{[16]}$. Desta forma, este trabalho objetivou verificar o efeito da sanitização utilizando água ozonizada na inativação de E. coli $\mathrm{O} 157: \mathrm{H} 7$ inoculada intencionalmente em alface americana.

\section{MATERIAL E MÉTODOS}

\section{Preparo e tratamento das amostras}

O experimento foi realizado no laboratório da Fazenda da Aeronáutica de Pirassununga, SP. Todos os ensaios foram realizados em duplicata. Para isto, dez amostras de alface americana foram adquiridas no comércio de Santo André, SP e transportadas sobrefrigeração, $4^{\circ} \mathrm{C}$, até o laboratório da Fazenda da Aeronáutica de Pirassununga, SP. Estas amostras foram preparadas, inoculadas com E. coli O157:H7 e posteriormente tratadas com água ozonizada. Os procedimentos utilizados para estudar a eficácia dos tratamentos com ozônio na descontaminação de alface foram aplicados simulando uma higienização das folhas em escala industrial. Todos os utensílios e equipamentos utilizados nos experimentos foram higienizados com detergente clorado (200 mg..-1 $)$, e enxaguados com água corrente. Para a preparação das amostras, as alfaces tiveram folhas externas defeituosas e danificadas removidas, assim como os talos. Porções de alfaces foram colocadas em peneira de aço inox onde foram lavadas em água corrente. 


\section{Micro-organismo e meios de cultura}

A cultura de E. coli O157:H7 ATCC 35150 foi obtida na Seção de Coleção de Culturas do Instituto Adolfo Lutz e mantida a $4^{\circ} \mathrm{C}$ em rampa de Ágar Triptona Soja (TSA) inclinado. Semanalmente a cultura foi repicada para manutenção da viabilidade das células [17]. A pesquisa de E. coli O157:H7 foi realizada partindo-se da inoculação em Caldo EC adicionado de novobiocina seguido de isolamento em Ágar Mac Conkey e Ágar Verde Brilhante [18].

\section{Preparo do inóculo}

A suspensão do micro-organismo foi preparada utilizando-se um tubo contendo $10 \mathrm{~mL}$ de meio de cultura Ágar Triptico Soja (TSA) inclinado, onde foi estriada a estirpe de E. coli O157:H7 e incubada a $35^{\circ} \mathrm{C}$, por 24 horas. Empregando-se $3 \mathrm{~mL}$ de solução fisiológica estéril $0,1 \%$, a cultura de E. coli crescida foi transferida para uma garrafa de Roux contendo $250 \mathrm{~mL}$ do mesmo meio de cultura (TSA). O frasco de Roux foi incubado a $35^{\circ} \mathrm{C}$ por 24 horas.

A cultura resultante na superfície do meio foi lavada com $50 \mathrm{~mL}$ de solução fisiológica $0,1 \%$ estéril, com o auxílio de pérolas de vidro. Foi ajustada a diluição para obter uma solução com $60 \%$ de transmitância no comprimento de onda de $580 \mathrm{~nm}$ empregando-se espectrofotômetro UV/VIS. Tal transmitância é equivalente a $10^{8}$ UFC. $\mathrm{mL}^{-1}$, verificada pelo método de contagem em placas [17].

\section{Inoculação}

As folhas de alfaces foram inoculadas com $E$. coli $\mathrm{O} 157: \mathrm{H} 7$ em câmara de fluxo laminar. Para este procedimento 2,5 $\mathrm{mL}$ da cultura foi suspensa em 2,5 L de água previamente esterilizada. $\mathrm{O}$ vegetal foi imerso e movimentado suavemente por 5 minutos para distribuição uniforme do inóculo.

Após a contaminação, as folhas foram retiradas utilizando-se uma peneira de aço inox estéril, facilitando dessa maneira o escoamento do excesso de água e a remoção do vegetal. Após o tratamento, as alfaces foram estocadas a $7^{\circ} \mathrm{C}$ por 24 horas para uma melhor aderência do micro-organismo nas folhas. Posteriormente, as amostras foram dividas em dois grupos: as que seriam tratadas com ozônio e as que seriam utilizadas para controle do processo, sendo realizada a enumeração inicial de E. coli O157:H7.

\section{Gerador de ozônio}

O equipamento utilizado na produção de ozônio foi fabricado pela empresa Panozon, constando de gerador de ozônio modelo PNZ 714, concentrador de oxigênio (90 a 95\% de pureza), tanque de contato e um sistema de injeção com bomba para filtração. $\mathrm{O}$ sistema possui também um tanque de gaseificação com a função de separar o ozônio que permaneceu na forma de gás e retirá-lo da tubulação, enviando o mesmo para um circuito interno onde é reduzido a oxigênio. A água ozonizada é recirculada em uma vazão de $20 \mathrm{~L} \cdot \mathrm{min}^{-1}$ para uma cuba de aço inoxidável com capacidade de 50 litros. $\mathrm{O}$ equipamento permite ajustar a concentração de ozônio entre 0,6 mg.L $L^{-1}$ a 1,2 mg.L $\mathrm{L}^{-1}$.

\section{Inativação da $E$. coli $\mathrm{O} 157: \mathrm{H} 7$ inoculada intencionalmente nas alfaces}

As alfaces contaminadas com E. coli $\mathrm{O} 157: \mathrm{H} 7$ foram expostas ao tratamento com ozônio. Para isto, as amostras de aproximadamente $150 \mathrm{~g}$ de alface foram submersas em tanque com $50 \mathrm{~L}$ de água na concentração de 1,0 mg.L.-1 de ozônio por um minuto. Após o tempo de processo, as amostras submersas foram retiradas com auxílio de uma cesta de aço inoxidável e armazenadas em sacos plásticos para enumeração dos micro-organismos sobreviventes.

\section{RESULTADOS E DISCUSSÃO}

A Tabela 1 apresenta as contagens iniciais de E. coli $\mathrm{O} 157: \mathrm{H} 7$ após a inoculação em alface e o número de reduções decimais obtidas após o processamento com água ozonizada. 
Tabela 1. Alfaces americanas contaminadas com E. coli $\mathrm{O} 157: \mathrm{H} 7$, expostas ao tratamento com água ozonizada à concentração de $1,0 \mathrm{mg} . \mathrm{L}^{-1}$ por 1 minuto.

\begin{tabular}{|c|c|c|c|}
\hline Amostra & $\begin{array}{c}\text { Contagem inicial de } E \text {. coli } \\
\text { O157:H7 (UFC.g }{ }^{-1} \text { ) }\end{array}$ & $\begin{array}{c}\text { Contagem de } E \text {. coli } \\
\text { O157:H7 após sanitização } \\
\left(\text { UFC.g }^{-1}\right)\end{array}$ & $\begin{array}{c}\text { Número Redução } \\
\text { Decimais* }\end{array}$ \\
\hline 1 & $8,3 \times 10^{5}$ & $1,3 \times 10^{3}$ & 2,81 \\
\hline 2 & $1,1 \times 10^{6}$ & $1,1 \times 10^{3}$ & 3,00 \\
\hline 3 & $3,4 \times 10^{6}$ & $8,1 \times 10^{2}$ & 3,62 \\
\hline 4 & $5,6 \times 10^{6}$ & $1,8 \times 10^{2}$ & 4,49 \\
\hline 5 & $4,5 \times 10^{6}$ & $1,1 \times 10^{3}$ & 3,61 \\
\hline 6 & $9,2 \times 10^{5}$ & $3,7 \times 10^{3}$ & 2,40 \\
\hline 7 & $8,0 \times 10^{5}$ & $1,4 \times 10^{3}$ & 2,76 \\
\hline 8 & $7,9 \times 10^{5}$ & $1,4 \times 10^{3}$ & 2,75 \\
\hline 9 & $2,3 \times 10^{6}$ & $1,1 \times 10^{3}$ & 3,32 \\
\hline 10 & $1,9 \times 10^{6}$ & $1,1 \times 10^{3}$ & 3,24 \\
\hline
\end{tabular}

* NRD $=\log ($ concentração inicial $)-\log ($ concentração final $)$

Os resultados da Tabela 1 mostram que a etapa de inoculação apresentou boa repetibilidade, com menos de um ciclo logaritmo de variação entre as amostras. Além disso, observa-se que a etapa de aderência não causou morte microbiana, uma vez que as contagens de E. coli antes da sanitização com água ozonizada foram compatíveis com a carga inoculada, de aproximadamente $10^{6} \mathrm{UFC} . \mathrm{g}^{-1}$.

O número de reduções decimais obtidas apresentou uma grande variação (entre 2,4 e 4,5), sendo que amostras com menores contagens iniciais $\left(10^{5}\right.$ UFC. $\left.^{-1}\right)$ resultaram em menores níveis de inativação ( $<3$ reduções decimais). Isso pode indicar que a aderência do micro-organismo na alface é função de sua contagem inicial, sendo que, em contagens mais altas, a aderência é menor pela formação de sobre camadas de micro-organismos. Assim, pode-se supor que com menor aderência na alface, o efeito do tratamento com ozônio pode ser potencializado, resultando em maior inativação microbiológica.

Takeuchi et al. ${ }^{[19]}$ observaram que as células de E. coli O157:H7 e Listeria monocytogenes aderem preferencialmente na região dos cortes, enquanto $P$. fluorescens o faz nas superfícies intactas e Salmonella spp adere tanto as superfícies intactas quanto a região dos cortes. Takeuchi \& Frank ${ }^{[20]}$ evidenciaram que E. coli
O157:H7 penetra nos tecidos atingindo uma profundidade de até $73 \mu \mathrm{m}$ e se aloja preferencialmente na junção das células da alface. Os autores demonstraram que na profundidade de 30 a 40 $\mu \mathrm{m}, 68 \%$ das células de E. coli O157:H7 sobrevivem ao tratamento com $200 \mathrm{mg}$ de cloro livre por litro, com redução de apenas 0,4 a 0,5 ciclos logarítmicos. Observa-se, que além da barreira física, a matéria orgânica que envolve as células reage com $\mathrm{o}$ sanitizante, reduzindo seu potencial antimicrobiano [20].

Estes estudos demonstrando que E. coli O157:H7 penetra nos tecidos internos da alface a partir das folhas e das raízes, explicam a ineficiência dos processos tradicionais de higienização e sanificação e evidenciam a importância da qualidade das águas de irrigação e dos adubos orgânicos empregados no cultivo da alface. Ou seja, quando estes materiais estiverem contaminados, a alface estará contaminada e o processamento mínimo seguido de sanitização não será capaz de eliminá-la [21]. Esta habilidade de penetração da E. coli corrobora a hipótese de que, com a contaminação em menor concentração, uma maior fração da E. coli inoculada intencionalmente conseguiu penetrar nos tecidos da alface, o que dificulta a sua inativação, enquanto que, para amostras inoculadas com aproximadamente um ciclo logaritmo a mais, a formação de sobre camadas de micro-organismo dificultou a penetração dos 
mesmos no alface, tornando-os mais vulneráveis ao processo de sanitização.

Vijayakumar \& Hall [22] estudaram a ação de vinagre de maçã ( $0,3 \%$ de ácido acético) e $180 \mathrm{mg} \cdot \mathrm{L}^{-1}$ de solução de cloro sobre E. coli em alfaces e observaram uma redução de 2,7 e 1,6 ciclos logarítmicos após 10 minutos de exposição em uma temperatura de $21^{\circ} \mathrm{C}$, respectivamente. Silva et al. [23] observaram 2,57 reduções decimais na população de E. coli O157:H7 utilizando $200 \mathrm{ppm}$ de dicloroisocianurato de sódio por 15 minutos em temperatura ambiente em alface, rúcula e chicória. Behrsing et al. ${ }^{[24]}$ avaliaram a eficiência do hipoclorito de cálcio contendo $100 \mathrm{mg}$ de cloro livre por litro nos tempos de 2 e 5 minutos, $\mathrm{pH}$ de 6,5 e temperatura ambiente $\left(25^{\circ} \mathrm{C}\right)$ sobre E. coli $\mathrm{O} 157: \mathrm{H} 7$ e obtiveram de resultado a redução de 1,3 e 1,8 ciclos logarítmicos, respectivamente. Assim, pode-se observar que os sanitizantes clorados requerem maiores concentrações e tempos de contato quando comparados à sanitização por água ozonizada. Portanto, verifica-se que o ozônio possui um maior poder de sanitização demandando tempos e concentrações inferiores aos necessários para o cloro e ácido acético.

\section{CONCLUSÃO}

O processo de sanitização de alfaces com água ozonizada foi capaz de promover reduções decimais de até 4,5 ciclos logarítmicos na população $E$. coli O157:H7. Desta forma, a utilização de água ozonizada é uma tecnologia promissora e uma alternativa interessante aos sanitizantes tradicionais devido à sua eficiência em baixas concentrações em um curto período de tempo.

\section{REFERÊNCIAS}

[1] Abreu IMO, Junqueira AMR, Peixoto JR, Oliveira SA. Qualidade microbiológica e produtividade de alface sob adubação química e orgânica. Food Sci Technol. 2010;30(Suppl.1):108-118.

[2] Rodrigues CS. Contaminação microbiológica em alface e couve comercializadas no varejo de Brasília - DF. Brasilia: Universidade de Brasilia, 2007.

[3] Madic J, Vingadassalon N, De Garam CP, Marault M, Scheutz F, Brugère H, Jamet E, Auvray F. Detection of Shiga toxin-producing Eschericbia coli serotypes O26:H11, O103:H2, O111:H8, O145:H28, and O157:H7 in raw-milk cheeses by using multiplex real-time PCR. Appl Environ Microbiol. 2011;77(6):2035-2041.

[4] Forsythe SJ. Microbiologia da Segurança Alimentar. Porto Alegre: Artmed; 2005.

[5] Bosilevac JM, Koohmaraie M. Prevalence and Characterization of Non-O157 Shiga Toxin-Producing Eschericbia coli Isolates from Commercial Ground Beef in the United States. Appl Environ Microbiol. 2011;77(6):21032112.

[6] Parish ME, Beuchat LR, Suslow TV, Harris LJ, Garret EH, Farber JN, Busta FF. Methods to reduce/eliminate pathogens from fresh and fresh-cut produce. Comprehensive reviews in food science and food safety. 2001;2.

[7] Mogharbel ADI, Masson ML. Hazard associates to the consumption of the lettuce, (Lactuca sativa), in natura. Alim. Nutr. 2005;16(1):83-88.

[8] Cavalcante DA, Leite Júnior BRC, Tribst AAL, Cristianini M. Microbiological quality of Minas Frescal cheese treated with ozonated water. International Food Research Journal. 2013;20(5):2911-2915.

[9] Cavalcante DA, Leite Júnior BRC, Tribst AAL, Cristianini M. Improvement of the raw milk microbiological quality by ozone treatment. International Food Research Journal. 2013;20(4):2017-2021.

[10] Brasil. Portaria ํo 2.914, de 12 de dezembro de 2011. Dispõe sobre procedimentos de controle e de vigilância da qualidade da água para consumo humano e seu padrão de potabilidade. Diário Oficial da União. 04 jan 2012. Seção 1:43-49.

[11] Cavalcante DA, Leite Júnior BRC, Tribst AAL, Cristianini M. Uso de ozônio gasoso na sanitização de câmaras frigoríficas. Rev. Inst. Laticínios Cândido Tostes. 2014;69(2):121-128.

[12] Achen M, Yousef AE. Efficacy of ozone against Escherichia coli O157:H7 on apples. J Food Sci. 2001;66(9):1380-1384.

[13] Sharma RR, Demirci A. Application of ozone for inactivation of Eschericbia coli $\mathrm{O} 157: \mathrm{H} 7$ on inoculated alfafa sprouts. Journal of Food Processing and Preservation. 2003;27:51-64.

[14] Cavalcante DA, Leite Júnior BRC, Tribst AAL, Cristianini M. Inativação de Escherichia coli O157:H7 e Bacillus subtilis por água ozonizada. B.CEPPA. 2014:32(1):105-112. 
[15] Beuchat LR. Standardization of a method to determine the efficacy of sanitizers in inactivating human pathogenic microorganisms on raw fruits and vegetables. J Food Prot. 2001;64(7):1079-1084.

[16] Rice RG. Ozone in the United States of America. Ozone: Science and Engineering. 1999;21(2):99-118.

[17] Farmacopéia Brasileira. 4.ed. São Paulo: Atheneu; 1988.

[18] Speck ML. Compendium of methods for microbiological examination of foods. Washington: APHA/Technical Committee on Microbiological for Foods; 1984.

[19] Takeuchi K, Matute CM, Hassan AN, Frank JF. Comparison of the attachment of Escherichia coli O157:H7, Listeria monocyogenes, Salmonella typhimurium and Pseudomonas fluorescens to lettuce leaves. J Food Prot. 2000;63(10):14331437.

[20] Takeuchi K, Frank JF. Penetration of Escherichia coli O157:H7 into lettuce tissues as affected by inoculum size and temperature and the effect of chlorine treatment on cell viability. J Food Prot. 2000;6(3):434-440.
[21] Goularte, L. Aplicação de processos combinados processamento mínimo e radiação ionizante (60Co) visando o aumento da segurança microbiológica de alface (Lactuca sativa, L.) [tese]. São Paulo: Faculdade de Ciências Farmacêuticas da USP; 2003.

[22] Vijayakumar C, Hall CE. Evaluation of household sanitizers for reducing levels of Escherichia coli on iceberg lettuce. J Food Prot.2002;65(10):1646-1650.

[23] Silva N, Silveira NFA, Yokoya F, Okazaki MM. Ocorrência de Escherichia coli O157:H7 em vegetais e resistência aos agentes de desinfecção de verduras. Food Sci Technol. 2003;23(2):167-173.

[24] Behrsing J, Winkler S, Franz P, Premier R. Efficacy of chlorine for inactivation of Escherichia coli on vegetables. Postharvest Biology and Technology. 2000;19:187-192. 